\title{
Predicting the Performance of Highway Embankment Slopes
}

\author{
Navid H. Jafari ${ }^{1, *}$, Anand Puppala ${ }^{2}$, Burak Boluk ${ }^{2}$, Jack A. Cadigan ${ }^{1}$, Sayantan Chakraborty ${ }^{2}$, Tejo Bheemasetti ${ }^{3}$, and \\ Jordan E. Pleasant ${ }^{1}$
}

${ }^{1}$ Department of Civil and Environmental Engineering, Louisiana State University, Baton Rouge, LA 70803

${ }^{2}$ Department of Civil Engineering, The University of Texas at Arlington, Arlington, TX 76019

${ }^{3}$ Department of Civil Engineering, South Dakota School of Mines \& Technology, Rapid City, SD 57701

\begin{abstract}
Resilience of transportation infrastructure, such as highway embankments, is critical to avoiding commuter delays and costly repairs. The majority of highway embankments in Louisiana and Texas are in marginal condition because the high-plasticity clays that are used during construction will moisten with time to significantly lower strengths. The ring shear tests demonstrate that the Gamez and Stark [1] empirical correlations are applicable to Texas and Louisiana soils. The soil water retention curves at each site were fitted to the Van Genuchten model [2]. For example, the air entry values vary from 0.013 to $0.053 \mathrm{kPa}-1 \mathrm{in}$ Louisiana and from 0.008 to $0.01 \mathrm{kPa}-1$ in Texas. The implications of this wide range of air entry values is that the matric suction pressure required to saturate and desaturate controls the pore-water pressure build-up during a rainfall event.
\end{abstract}

\section{Introduction}

A significant number of highway slope failures are reported each year in Louisiana and Texas because the native soils mostly consist of high plasticity clays. Initial research attributed highway slope failures to the presence of high plasticity clays that undergo significant volumetric changes from seasonal climatic fluctuation. Moreover, it was identified that weather cycles (i.e., wetting-drying) resulted in desiccation cracks, which exposed the embankment fill material to increased moisture from precipitation. With increased moisture and softening of the soil, the shear strength reduced from a peak strength to fully softened strength. Because of the significantly lower strengths, frequent slope failures occur after rain events. More importantly, the frequency of such highway slope failures is predicted to increase in the future as the weathering conditions are impacted by higher rainfall intensities and longer durations of drought-like conditions. Considering these conditions, there is an urgent and important need to develop a predictive tool for identifying such a high-risk location.

The aim of this study is to develop the methodology and present findings for a predictive tool to identify high-risk slopes. To achieve this objective, medium to high plasticity soil samples were collected from slope failures from varying geological formations across the states of Texas and Louisiana. The Louisiana sites are located along I-55 near Hammond and along I-10 in Welsh. For the Texas sites, Site 1 is located in Denison along U.S 75 Frontage Road. Sites 2 and 3 are located in
Paris along Highway 82 and nearby N Main Street. The research program included comprehensive laboratory tests such as physical index tests, shear strengths, and hydraulic properties. Further, inverse stability analyses were performed using the laboratory soil properties to evaluate possible pore-water pressure conditions that could have triggered the slope failures.

\section{Laboratory testing}

\subsection{Fully softened shear strength}

To measure the fully softened shear strength, the modified Bromhead ring shear apparatus described by Stark and Eid [3] was used in accordance with ASTM (D7608-10) to determine FSS envelopes. The modified Bromhead ring shear apparatus uses an annular specimen with an inside diameter of $70 \mathrm{~mm}$ (2.75 in) and an outside diameter of $100 \mathrm{~mm}$ (4 in). The I-55 soil sample is from the Hammond, LA site, while the I-10 sample comes from exit 54 which contains 4 separate embankment failures at the overpass. The ring shear tests were performed at effective normal stresses of $12 \mathrm{kPa}$, $50 \mathrm{kPa}$, and $100 \mathrm{kPa}$. The sample preparation involves mixing the soil at 1.5 times the liquid limit, consolidated to the effective normal stress, and sheared at a rate of $0.018 \mathrm{~mm} / \mathrm{min}$. Figure 1 shows the components of the ring shear device.

\footnotetext{
* Corresponding author: njafari@1su.edu
} 


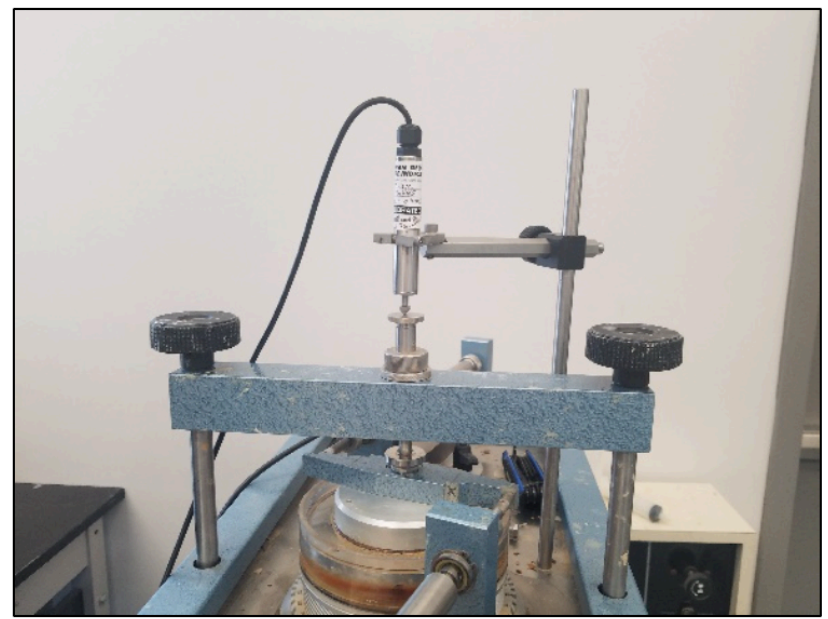

Fig. 1. Components of the ring shear device test setup.

Three main correlations have been published to estimate the FSS envelope, Stark and Eid [3] augmented by Stark et al. [4], Stark and Hussain [5], and Gamez and Stark [1]. The correlations estimate the effective normal stress-dependent FSS envelope using liquid limit, claysize fraction, and plasticity index. Figure 2 shows the correlations from Gamez and Stark [1]. To develop the non-linear strength envelop, the clay-size fraction (CF) and liquid limit (LL) are measured using the hydrometer and Atterberg cup, respectively. With these properties, the secant friction angle is evaluated for normal effective stresses of $12 \mathrm{kPa}, 50 \mathrm{kPa}$, and $100 \mathrm{kPa}$. The non-linear shear strength is formed by using the secant friction angle and normal effective stress. For normally consolidated soils, the cohesion intercept is zero.

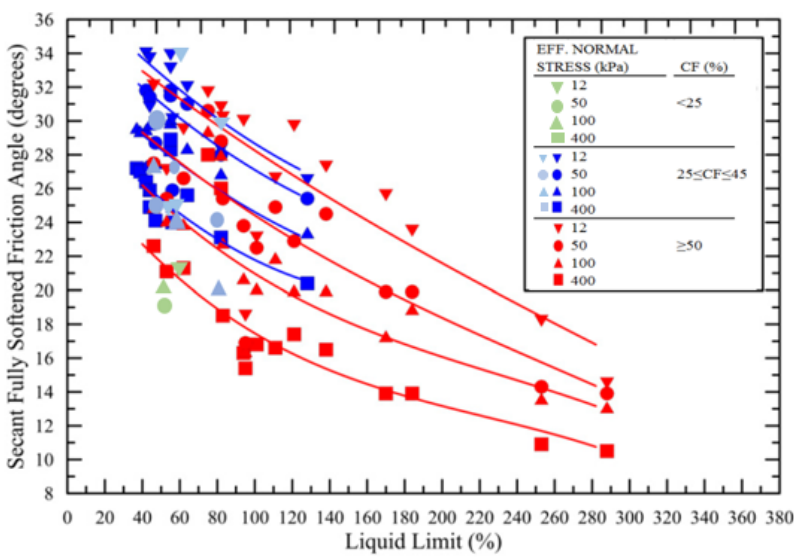

Fig. 2. Drained fully softened friction angle correlation for clay-size fraction [1].

\subsection{Soil water retention curve (SWRC)}

During the drought season, the degree of saturation of the embankment soil drops substantially leading to changes in the hydraulic conductivity. SWRC tests for the soils were conducted to predict the infiltration and pore-water pressure increase in the embankments. SWRC depends on the soil type, grain size distribution, density, and temperature. Fredlund [6] describes the entire SWRC using three zones: (1) boundary effect

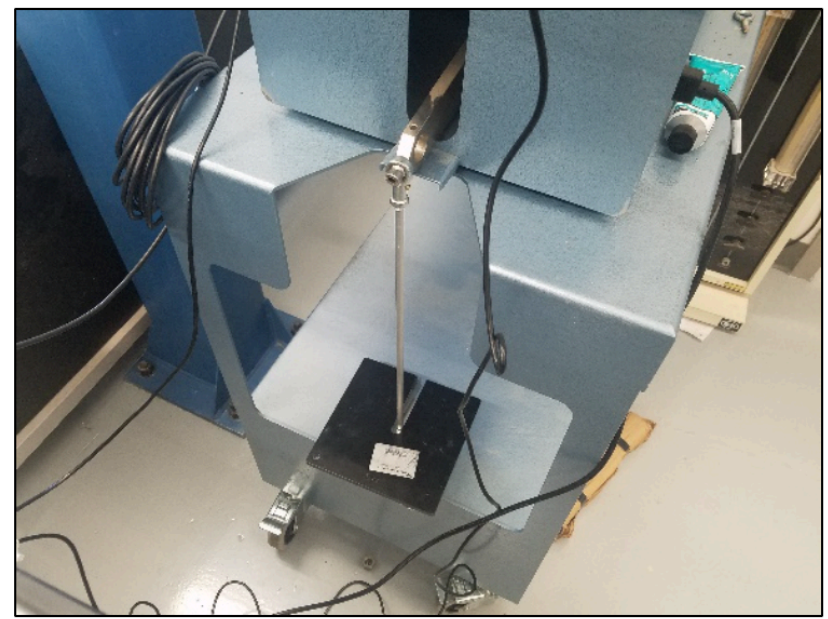

zone, (2) transition zone, and (3) residual zone. Boundary effect zone indicates negligible change in water content with an increase in suction level. The transition zone is represented by a sudden decrease in water content with corresponding increase in suction. The residual zone indicates minimal water content change with increase in suction level. These zones are separated by air-entry value and residual suction level. There are different laboratory test methods to measure the components of the total suction and matric suction to develop SWRC. For this study, the Tempe cell apparatus and the WP4C Dew Point Potentiometer apparatus were utilized. The Tempe cell apparatus was used for relatively low suction range, i.e. from 0 to 10,442 psf $(500 \mathrm{kPa})$ whereas the WP4C was used for high suction values.

\subsection{Tempe cell apparatus}

The Tempe cell apparatus applies and maintains matric suction on the soil specimens by using the axis translation technique proposed by Hilf [7]. The soil sample is placed on the HAE ceramic disk, and then the retaining cylinder is covered before applying the required air pressure (Figure 3). The test is started by applying a small air pressure $(\sim 5 \mathrm{kPa})$ on a saturated soil specimen and the volume of water expelled from the specimen before reaching equilibrium in recorded. This generates the first point on the SWRC, and additional points are obtained by changing the applied air pressure in the Tempe cell. The air-water menisci present in the pores of the saturated ceramic disk prevents the air to pass through the disk but allows water from the soil specimen to flow through it. This phenomenon enables maintaining the desired air pressure and suction level required to perform the test. At the end of the test, the water content of the specimen at different applied suction levels is back-calculated based on the volume of water expelled from the specimen. In this research, a ceramic disk with an air entry value of 5 bars $(500 \mathrm{kPa})$ was used. To determine the remaining portion of the SWRC corresponding to relatively high suction range, the Dew Point Potentiometer apparatus was utilized. 

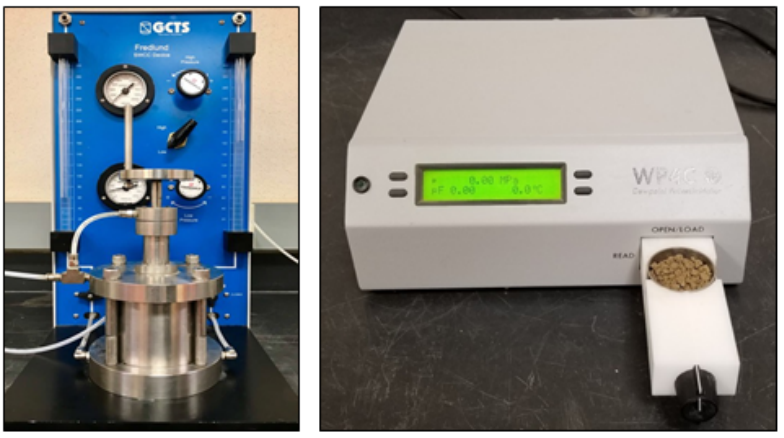

Fig. 3. Tempe cell apparatus (left) and Dew point potentiometer device (right).

\subsection{Dew point potentiometer}

WP4C Dew Point Potentiometer determines the water presence for high suction range by determining the amount of the relative humidity above the soil. WP4C apparatus adopts the chilled-mirror technique as given in ASTM D6836. The soil sample is placed in the closed chamber that has a mirror, optical sensors, and temperature sensors. At equilibrium stage, the amount of relative humidity is in relationship with the soil suction level. Figure 3 shows the WP4C Dew Potentiometer apparatus used in this research study.

The drying path of SWRC was obtained using Tempe cell and Dew Point Potentiometer. For less than $500 \mathrm{kPa}$ suction value, Tempe cell apparatus was used. The required amount of air-dried soil was pulverized and passed through the No. 40 sieve. The soil samples of $2.54 \mathrm{~cm}$ height and $6.35 \mathrm{~cm}$ diameter were prepared at a maximum dry density of $95 \%$ by using the OMC value obtained from standard compaction test. The samples were compacted under static compaction with $1.7 \mathrm{~mm} /$ min compaction rate. To ensure the uniform distribution of moisture throughout the sample, they were kept in the humidity-controlled room for 48 hours. Specimens were confined in all the directions and were left submerged in the distilled water for at least 72 hours to obtain $100 \%$ degree of saturation. At the same time, the ceramic disk was saturated in Tempe cell at a pressure of $100 \mathrm{kPa}$ for 24 hours. The SWRC was obtained by changing the air pressure while keeping the pore water pressure equal to the atmospheric pressure. Once the air pressure was applied in the cell, the water present in the pores was expelled from the specimen until the water and air phase reached an equilibrium. The matric suction was increased in steps and water content was calculated at every step by recording the amount of water leaving the sample.

For higher suction ranges, the WP4C apparatus was utilized. The total suction measured using WP4C Potentiometer was assumed to be equal to the soil matric suction due to absence of appreciable quantity of dissolved salts. The sample holder was half filled (approximate volume of $7 \mathrm{~cm}^{3}$ ) with the soil to be tested, thoroughly cleaned to prevent contact with the relative humidity sensor and placed in the chamber. After locking the container, the presence of relative humidity above the soil was measured. When the relative humidity reaches the equilibrium, the potentiometer displays the total matric suction of the soil specimen. At each step, soil water content was measured and the SWRC plotted. Figure 4 shows an example of the SWRC from Denison, TX.

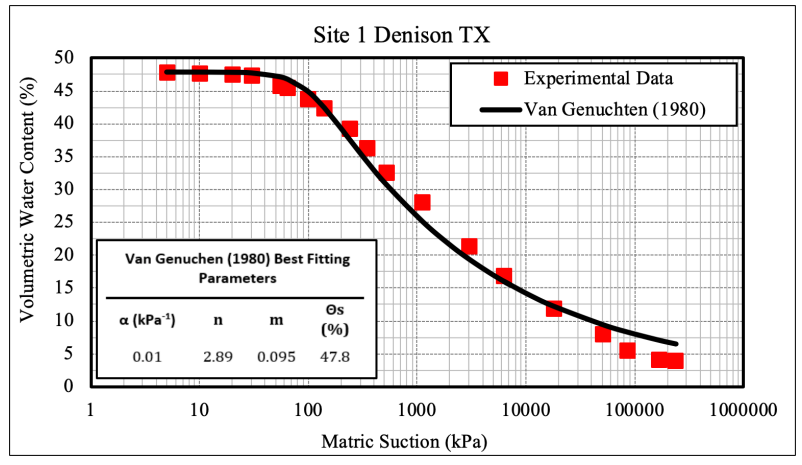

Fig. 4. SWRC of Texas Site 1 soil using the Van Genuchten [2] model.

\subsection{Predicting unsaturated hydraulic conductivity}

To predict the SWRC, many empirical equations are available. These equations can be divided into two and three constant fitting parameters and are utilized to fit the obtained SWRC data. In this study, the Van Genuchten [2] model was implemented and it uses three constant fitting parameters:

$$
\Theta=\frac{\theta-\theta_{r}}{\theta_{s}-\theta_{r}}=\left(\frac{1}{1+(\alpha \psi)^{n}}\right)^{m}
$$

where $\theta=$ volumetric water content, $\theta_{s}=$ saturated water content, $\theta_{r}=$ residual water content, and $\alpha, n$ and $m=$ constant soil parameters.

In the Van Genuchten [2] best fitting equation, $\alpha, n$ and $m$ are related to inverse of air entry value of soil, soil pore size distribution, and symmetry of the curve, respectively. Soils with smaller particle sizes correspond to smaller $\mathrm{n}$ value, whereas soil with high air entry value corresponds to a smaller $\alpha$ value. The SWRC along with the determined unsaturated soil parameters are presented in Figure 4. The unsaturated hydraulic conductivity value could then be estimated using these Van Genuchten model [2] parameters.

\section{Climate coupled modeling}

To evaluate the effects of climate on high plasticity embankments, a climate-coupled model was designed. Using an embankment in Baton Rouge, LA as a case study, the effects of climate coupling on compacted clay embankments was investigated using the finite element packages in GeoStudio 2018. The site in Baton Rouge is not one of the three aforementioned locations and was selected because high quality weather station data was available less than 2 miles, which was not the case for 
sites in Texas. The embankment is about $8 \mathrm{~m}$ in height with slopes of $3 \mathrm{H}: 1 \mathrm{~V}$. The embankment consists of silty clay to high plasticity clay, similar to the other embankments tested in this project. Climatic data was obtained from the Louisiana State University Agriclimatic Center (Figure 5), which has a network of weather stations across the state. The model was run for approximately two years, with the first year used as spinup time into realistic physical conditions
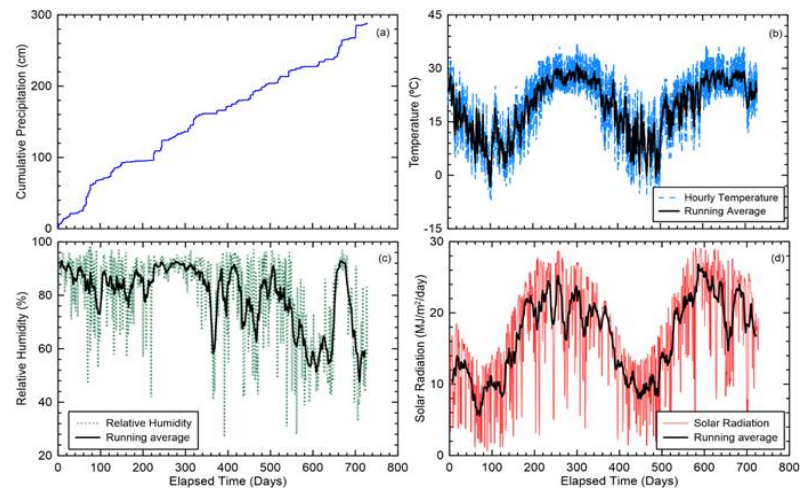

Fig. 5. Climatic data obtained from the Louisiana state university agriclimatic data system.

Coupling the climatic data to the embankment illustrates the elevated pore water pressures developed during rain events. As seen in Figure 6, the phreatic surface in the high plasticity embankment progresses through the core of the high plasticity embankment and correspondingly raises pore water pressures on the slope faces. Through the model run, a variety of conditions were present, including drought and heavy precipitation. Following heavy precipitation events, the high plasticity embankments seem to stay saturated longer than initially expected.

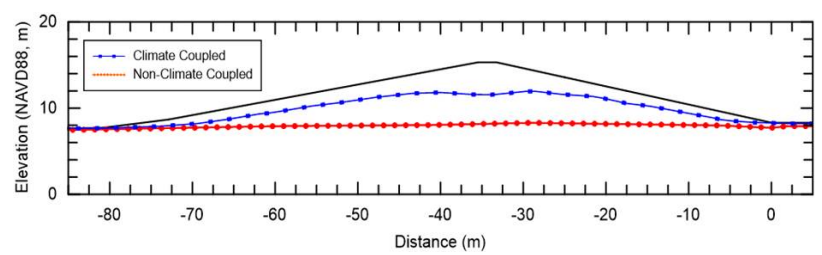

Fig. 6. Elevated phreatic surface location in climate coupled model.

\section{Conclusions}

The current study found that literature and experiments on Louisiana highway embankment failures was lacking. The ring shear tests demonstrate that the Gamez and Stark [1] correlations are applicable to Texas and Louisiana soils. The unsaturated hydraulic properties of Texas and Louisiana soils were evaluated. The air entry values vary from 0.013 to $0.053 \mathrm{kPa}-1$ in Louisiana and from 0.008 to $0.01 \mathrm{kPa}-1$. The implications of this wide range are that the matric suction pressure required to saturate and desaturate the soil also controls the pore- water pressure build-up during a rainfall event. Climate coupled modeling provides the ability to visualize transient pore-water pressure development in response to climatic conditions and should be utilized in the design process and back analysis of embankment failures of high plasticity clays. During the design process, the effect of desiccation crack development and subsequent hydraulic conductivity increase should be considered under various climatic scenarios. A first order predictive framework is proposed on the lessons learned, but case studies are needed to verify and further expand into a heat map. A framework that can accurately predict when and where a failure is currently elusive because of the variability in soil properties, e.g., unsaturated properties, peak or fully softened strength, and presence of tension cracks. However, a classification system that is site specific to a DOT district or region can be developed based on the proposed framework. The outcome is to take representative slopes with engineering properties and provide likelihood of failure with rainfall totals.

\section{References}

1. Gamez, J. and Stark, T.D. (2014). Fully Softened Shear Strength at Low Stresses for Levee and Embankment Design. ASCE Journal of Geotechnical and Geoenvironmental Engineering, June. 06014010-1-06014010-6.

2. Van Genuchten, M.T. (1980). A closed-form equation for predicting the hydraulic conductivity of unsaturated soils. Soil Science Society American Journal, 44, 892- 898.

3. Stark, T.D., and Eid, H.T. (1993). Modified Bromhead ring shear apparatus. Geotech. Test. J., 16(1), 100-107.

4. Stark, T.D., et al. (2005). Drained Shear Strength Parameters for Analysis of Landslides. ASCE Journal of Geotechnical and Geoenvironmental Engineering, 131(5), 575-588.

5. Stark, T.D., and Hussain, M. (2013). Empirical correlations: Drained shear strength for slope stability analyses. ASCE Journal of Geotechnical and Geoenvironmental Engineering, June 2013, 139(6), 853-862.

6. Fredlund, D.G. (2006). The Terzaghi Lecture: Unsaturated soil mechanics in engineering practice. ASCE Journal of Geotechnical and Geoenvironmental Engineering, 132(3), 286- 321.

7. Hilf, J.W. (1956). An Investigation of Pore-Water Pressure in Compacted Cohesive Soils. Tech. Memo. 654, U.S. Department of the Interior, Bureau of Reclamation Design and construction Div, Denver, Colorado. 